\title{
Polish Annals of Medicine
}

\author{
journal homepage: https://www.paom.pl
}

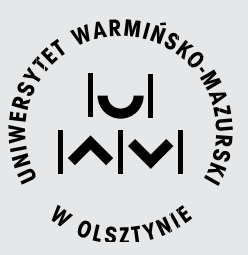

Original article

\section{Poor lumbar movement control in males exercising at the gym: Assessment and training using pressure biofeedback unit}

\author{
Szymon Gryckiewicz ${ }^{1,2}$, Michat Hadata ${ }^{2}$, Teresa Gniewek ${ }^{3}$, Agnieszka fankowicz-Szymańska ${ }^{4}$ \\ ${ }^{1}$ Orvit Clinic, Toruń, Poland \\ ${ }^{2}$ Fizjo-Sport, Rzeszów, Poland \\ ${ }^{3}$ AWF Kraków, Poland \\ ${ }^{3}$ High Shool in Tarnow, Poland
}

\section{ARTICLE INFO}

Article history

Received 1 May 2017

Accepted 18 September 2017

Available online 7 March 2018

Keywords

Movement system

Lumbar extension

Low back pain

Pressure biofeedback unit

Prevention

Doi

10.29089/2017.17.00031

User license

This work is licensed under a

Creative Commons Attribution -

NonCommercial - NoDerivatives

4.0 International License.

(cc) BY-NC-ND

\section{ABSTRACT}

Introduction: Mechanical overloading is one of the causes of low back pain (LBP). Dysfunction of movement control and impaired movement patterns can constitute a potential risk factor for LBP development.

A im: The aim of the study was to assess lumbar extension control in young physically active males with the use of the pressure biofeedback unit (PBU) in the context of the most relevant literature.

Material and methods: Randomly 30 young men regularly training at the gym (mean age 19.7 years) were selected to participate in the study. The survey contained basic data (such as: age, profession, height and weight). The dynamic assessment included abdominal muscle endurance test and three tests for movement extension control (the single straight leg test, the double straight leg test in the supine position and the bench press test).

Results and discussion: During the single straight leg test, $63 \%$ of the participants did not control lumbar extension for the right leg, and $37 \%$ for the left leg. In the double straight leg test, $77 \%$ of the participants did not control lumbar extension. During the bench press tests, $22 \%$ did not control lumbar extension during barbell lowering and 30\% during lifting. Repeated excessive extension, which is frequently inadequately controlled by the neuromuscular system, may cause damage to the spinous processes and the soft tissue.

Conclusions: Individuals training at the gym may have a tendency towards uncontrolled lumbar extension. PBU can be useful tool in view of the prevalence of LBP. 


\section{INTRODUCTION}

It is estimated that approximately $80 \%$ of the population experience at least one episode of low back pain (LBP) in their lifetimes. ${ }^{1,2}$ LBP is a major cause of functional disability and pain to the patient, as well as a financial burden to the healthcare system, employers and also for the society. ${ }^{2-6} \mathrm{LBP}$ is classified into: primary or secondary, mechanical or nonmechanical, with or without neurological complications, or associated with inflammatory, infectious, neoplastic, psychosomatic or other diseases. ${ }^{4}$

The main causes of LBP, or more specifically, mechanical LBP (MLBP), are connected with the musculoskeletal system (incorrect, forced body posture) and wrong dynamics (incorrect biomechanics, impaired movement patterns, and incorrect lumbopelvic-hip rhythm., ${ }^{4,-10}$ Van Dillen et al. emphasize the need for a standardized classification system of homogenous MLBP subtypes. ${ }^{7}$ Both the movement system impairment (MSI) and the Kinetic Control standardize the classification of MLBP focusing mainly on the diagnosis of uncontrolled movement in dynamics. ${ }^{7,11-16}$

Identifying and classifying movement faults are becoming an essential tool in contemporary rehabilitative neuromusculoskeletal practice. ${ }^{11,16-18}$ Many arguments support the existence of a relationship between LBP, impaired movement patterns, muscle activation and coordination of synergistic muscles. ${ }^{7,9,11,12,15,19-22}$

\section{AIM}

The aim of the study was to assess lumbar extension control in young physically active males with the use of the pressure biofeedback unit (PBU) in the context of the most relevant literature.

\section{MATERIAL AND METHODS}

\subsection{Participants}

The participants consisted of 30 men regularly exercising in the gym. The mean age of participants was 19.7 (SD 4.06). The inclusion criterion was training for a minimum of 3 months at the gym. Exclusion criteria were training for fewer periods of time then 3 months. Participants were selected randomly.

\subsection{Questionnaire}

The participants were additionally asked to complete a purpose-designed survey containing basic data, such as: age, profession, height and weight. The survey also contained exercise-related questions and questions concerning the participants' awareness of correct execution of the bench press.

\subsection{Dynamic assessment}

The dynamic assessment included selected motor tests (MSI, Kinetic Control) facilitating the assessment of lumbar extension control. During the test, the participants

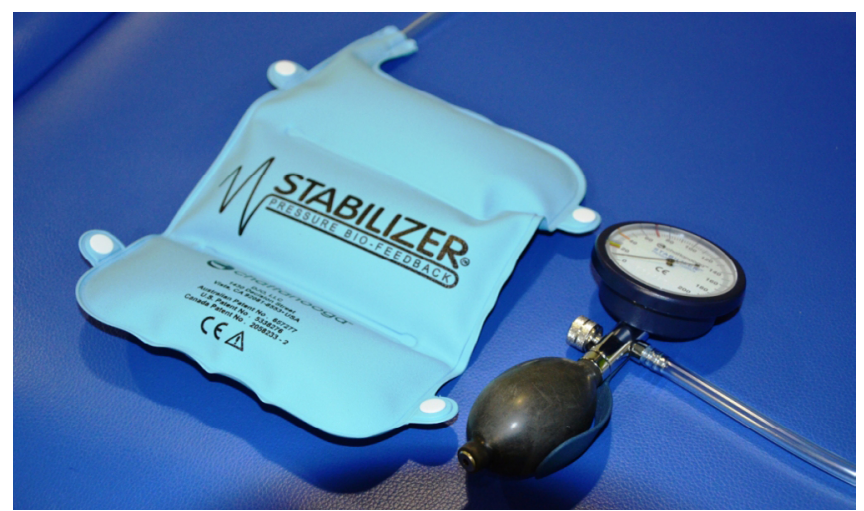

Figure 1. Pressure biofeedback unit.
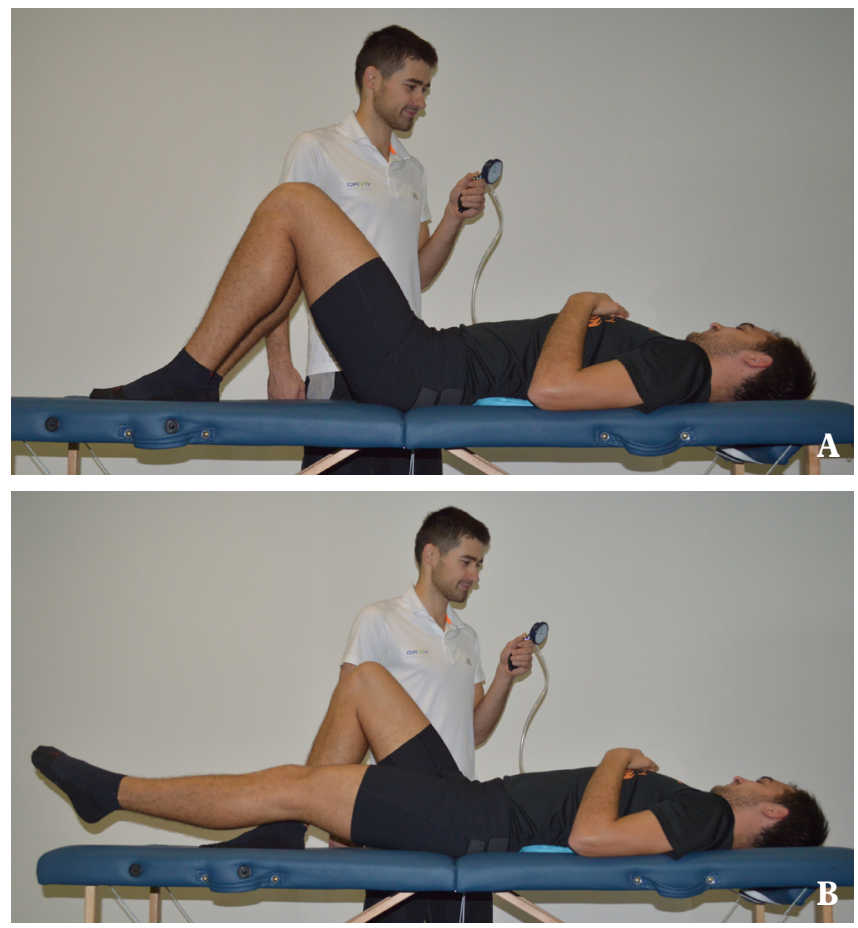

Figure 2. Single straight leg lower test: starting position (A), leg extension (B).

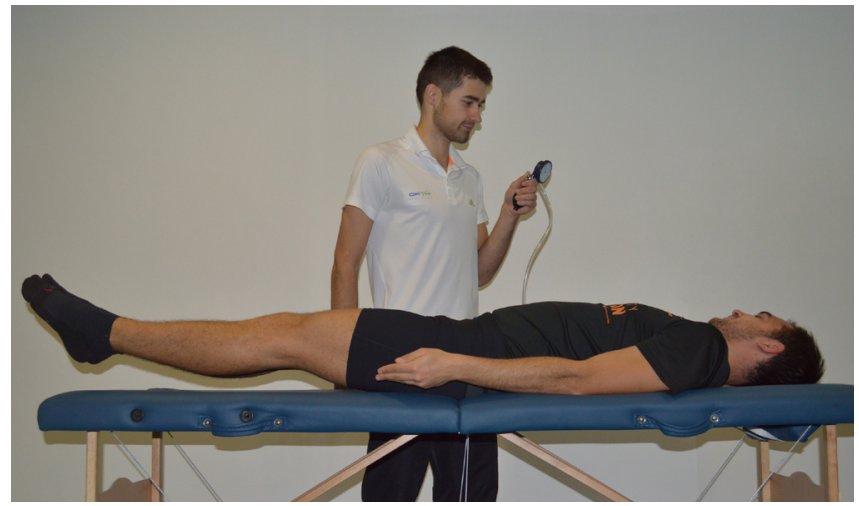

Figure 3. Double straight leg lower test.

were in a supine position, with the stabilizer PBU (Figure 1) placed under the lumbar section, with its centre at $L 3$. When the lumbar section was in a neutral position, the PBU was pumped to $40 \mathrm{~mm} \mathrm{Hg}$. Next, from the starting position 
Table 1. Tests used for dynamic assessment of participants.

\begin{tabular}{|c|c|c|}
\hline Test & Assessed feature & Norm \\
\hline $\begin{array}{l}\text { Hip extension } \\
\text { asymmetrical- } \\
\text { ly to the PBU }\end{array}$ & $\begin{array}{l}\text { Extension con- } \\
\text { trol short/uni- } \\
\text { lateral lever }\end{array}$ & $\begin{array}{l} \pm 5 \mathrm{~mm} \mathrm{Hg}^{23} \\
\pm 10 \mathrm{~mm} \mathrm{Hg}^{13} \\
- \text { due to the short/unilateral lever, the } \\
\text { norm applied in this test was } \pm 5 \mathrm{~mm} \mathrm{Hg}\end{array}$ \\
\hline $\begin{array}{l}\text { Hip extension } \\
\text { symmetrically } \\
\text { to the PBU }\end{array}$ & $\begin{array}{l}\text { Extension con- } \\
\text { trol long lever }\end{array}$ & $\begin{array}{l} \pm 5 \mathrm{~mm} \mathrm{Hg}^{23} \\
\pm 10 \mathrm{~mm} \mathrm{Hg}{ }^{13} \\
- \text { due to the long lever, the norm ap- } \\
\text { plied in this test had a higher margin: } \\
\pm 10 \mathrm{~mm} \mathrm{Hg} \text { (to the participants' ben- } \\
\text { efit) }\end{array}$ \\
\hline Bench press & $\begin{array}{l}\text { Extension con- } \\
\text { trol (high load) }\end{array}$ & $\begin{array}{l} \pm 5 \mathrm{~mm} \mathrm{Hg} \text { in all movement tests in } \\
\text { supine position } \\
\pm 10 \mathrm{~mm} \mathrm{Hg}^{23} \text { all motor tests in su- } \\
\text { pine position } \\
- \text { the norm applied in this test } \\
\text { had a higher margin: } \pm 10 \mathrm{~mm} \\
\mathrm{Hg} \text { (to the participants' benefit) } \\
- \text { the lifted weight } 60 \% \times 1 \mathrm{RM}\end{array}$ \\
\hline
\end{tabular}

(Figure 2A), the participant was asked to perform a single leg movement to $0^{\circ}$ hip extension (Figure $2 \mathrm{~B}$ ) and return to the starting position, maintaining $40 \mathrm{~mm} \mathrm{Hg}$ on the PBU. The test was performed for each leg, with an acceptable margin of error of $\pm 5 \mathrm{~mm} \mathrm{Hg}$. The exercise progressed to double leg extension and return to the starting position (Figure 3 ). The acceptable margin of error was $\pm 10 \mathrm{~mm} \mathrm{Hg}$. In both exercises, the arms were crossed over the chest or positioned alongside the body, with the inner sides leaning against the table. ${ }^{13}$ The maximum deviation from the norm (norm 40 $\mathrm{mmHg}$ on the PBU) was recorded for both tests in three positions: during initiation of movement (lifting the leg off the ground), during single/double leg extension, and during return to the starting position.

Each participant had the possibility to perform three trials with visual monitoring of the PBU value. The actual test was then carried out without visual feedback and the obtained result was recorded on a patient's chart.

The stability of the lumbar section during the bench press was assessed with the PBU. The lifted weight was $60 \%$ of the maximum load $(60 \% 1 R M)$. The participants performed two trials repeats with visual feedback. The third repeat constituted the actual test; the lowest values at barbell lowering and lifting were recorded. The tests are presented in Table 1.

\subsection{Statistical analyses}

The obtained results were analysed statistically in order to identify the relationships between variables. Assessment was based on Spearman's rank correlation coefficient. A correlation was considered significant if the value of $P$ was less than $0.05(P<0.05)$. The analysis also included scientific data concerning the use of PBU both in assessment and in training in individuals with lumbar extension dysfunction.

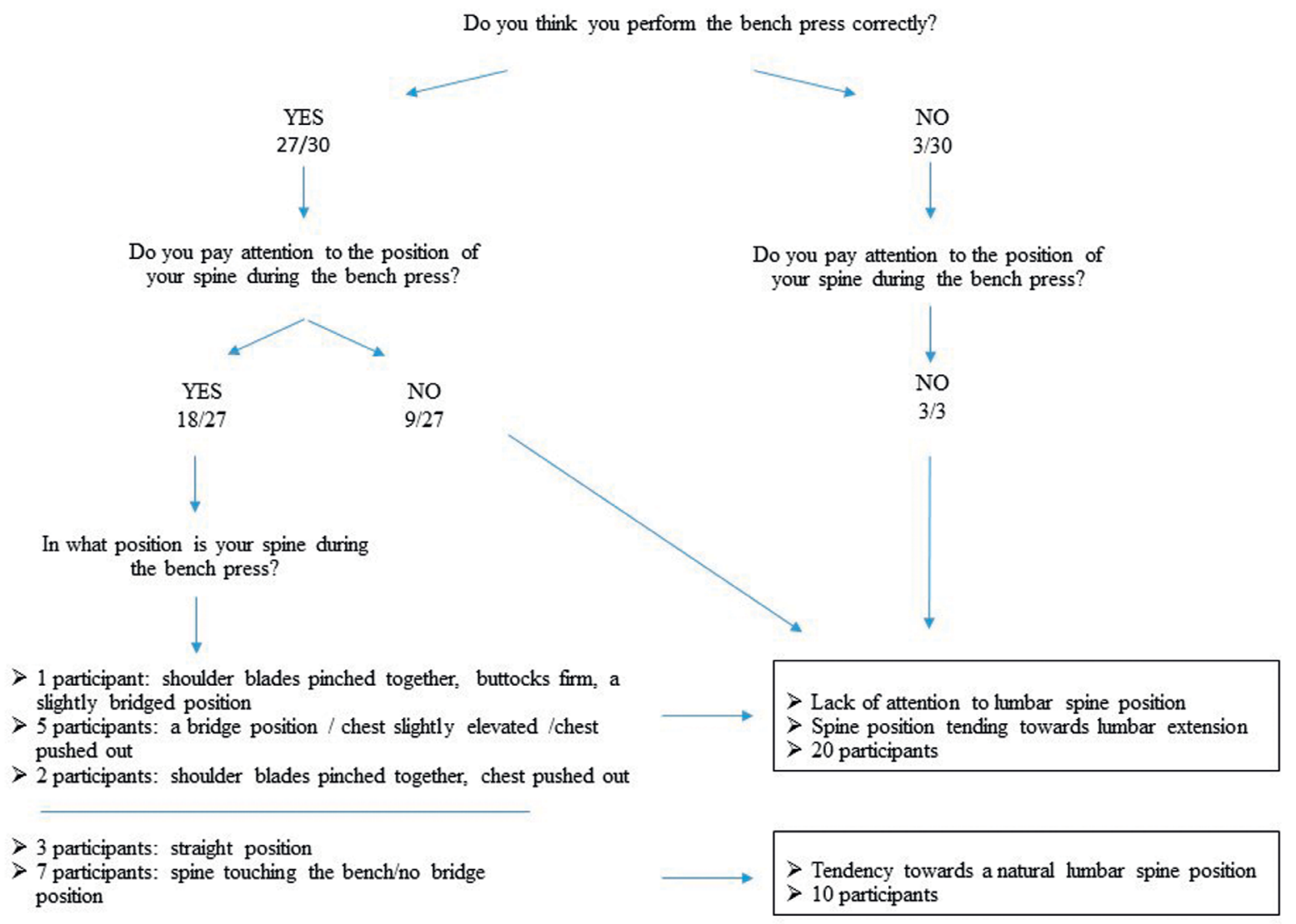

Figure 4. Questions associated with awareness of low back alignment during bench press 


\section{RESULTS}

\subsection{Survey}

The survey also contained exercise-related questions and questions concerning the participants' awareness of correct execution of the bench press. The obtained data is presented in Figure 4.

\subsection{Dynamic tests}

In movement tests assessing extension control in asymmetrical extension of one leg (short/unilateral lever) (Figure 2), $63 \%$ of the participants did not control right leg extension $(<35 \mathrm{~mm} \mathrm{Hg}$ ) and $7 \%$ generated compensation, both towards extension and flexion ( $>45 \mathrm{~mm} \mathrm{Hg}$ ). During left leg extension, $37 \%$ of the participants did not control the extension of the lumbar section. In the symmetrical extension of both legs (long lever) (Figure 3), 77\% of the participants did not control extension (PBU $<30 \mathrm{~mm} \mathrm{Hg}$ ) especially when they were lowering their legs, whilst $6 \%$ showed lack of control of both extension and flexion (PBU $>50 \mathrm{~mm} \mathrm{Hg}$ ) of the lumbar spine.

During the bench press exercise with PBU assessment, 7 participants (23\%) did not control the position of the lumbar section when lowering $(<30 \mathrm{~mm} \mathrm{Hg})$ and $9(30 \%)$ when lifting the barbell $(<30 \mathrm{~mm} \mathrm{Hg})$.

The statistical analysis of correlations of the different tests is presented in Table 2, where $R$ refers to the strength and direction of the relationship. For the bench press test, a significant correlation was observed for the ASIS-PSIS difference $\left(-0.44^{\star}\right)$ and for the two stages of the bench press: barbell lowering and lifting $\left(0.37^{\star}\right)$. The individual stages of tests (asymmetrical hip extension, symmetrical hip extension) performed with the PBU also correlated with one another (Table 2). Uncontrolled rotation was not assessed. Table 2 shows statistically significant correlations.

\section{DISCUSSION}

The spinous processes, intervertebral discs and joints, all passively limit lumbar hyperextension. Repeated excessive extension, which is frequently inadequately controlled by the neuromuscular system, may cause damage to the spinous processes and the soft tissue between them. If the spinous processes are widely spaced, the apophyseal joints are likely to become damaged first. ${ }^{24}$ Additionally, excessive extension may cause damage to the interspinous ligament, connected with the mechanism of intervertebral disc damage. ${ }^{11}$

According to Chimenti et al., one of the activity-related factors for LBP may be an impaired lumbopelvic pattern, repeated during sports and every-day activities. ${ }^{9}$ Uncontrolled lumbar extension was observed during motor control tests in the young male group. At low load, 37\% of the participants experienced problems with the test regarding left leg movement and $70 \%$ regarding right leg movement. At high load, $83 \%$ of the participants experienced problems with the exercise (double leg movement). During bench-press test
Table 2. Selected statistically significant correlations.

\begin{tabular}{l|r} 
Correlated variables & $R$ \\
Test with the PBU: right leg extension vs. left leg extension & $0.38^{\star}$ \\
Test with the PBU: return from right leg extension vs. return & $0.68^{\star}$ \\
from left leg extension & \\
Test with the PBU: initiation of double leg extension vs. right & $0.39 \star$ \\
leg extension & \\
Test with the PBU: initiation of double leg extension vs initia- \\
tion of left leg extension \\
$\begin{array}{l}\text { Test with the PBU: barbell lowering vs. ASIS to PSIS height } \\
\text { difference }\end{array}$ \\
Test with the PBU: barbell lowering vs. lifting
\end{tabular}

$\star$ Statistically significant

$23 \%$ (lowering phase) and 30\% (lifting phase) of participants experienced uncontrolled lumbar extension.

The movement dysfunction is identified by a series of clinical tests. ${ }^{13,14,19,25}$ The lower limb test in a supine position is commonly used to diagnose MLBP and to assess patients' motor ability in order to determine the direction of pain..$^{9,11,13,14,26}$ Roussel et al. studied the correlation between musculoskeletal system injuries and lumbar movement control in dancers. ${ }^{14}$ The tests included the so-called 'knee lift abdominal test' (KLAT), whereby the individual is in a supine position, with one leg bent at $90^{\circ}$, maintaining lumbar stability (the PBU was also used). The test is used to assess lumbar flexion and extension control. ${ }^{11,13}$ The KLAT, together with the 'standing bow' test had a 78\% correlation for increased risk of lower limb or lumbar injury. By contrast, a history of LBP or articular hypermobility (typical in dancers) did not indicate an increased risk of injury in the studied group. According to Hodges and Moseley, pain may lead to movement control disorders and vice versa: impaired coordination or timing delay may lead to a higher risk of musculoskeletal injury. ${ }^{22}$ Although the interpretation of movement tests does not fully explain the causes of lumbar pain, it shows the validity of extension control tests. A positive movement test result obtained by a healthy patient (without pain), may be a sign of weak neuromusculoskeletal coordination. ${ }^{11,13,20}$

The patient's objective during tests/exercises with the PBU is to maintain the lumbar section in the most neutral position possible..$^{27,28}$ According to Panjabi's core stability theory, training the neuromuscular system minimizes passive structure overload. ${ }^{29-31}$ The main advantage of the PBU during testing or training is feedback, which facilitates the elimination of lumbar compensation. ${ }^{27,28}$

Awareness and cognitive work is an important key element not only in back pain therapy but also in prevention and sport training. Tests with the use of the PBU facilitate the assessment and awareness of quality of lumbar extension control training. Lack of eccentric control of this movement during basic everyday activities very often generates an excessive amount of lumbar extension movement, thus contributing to MLBP. ${ }^{11,13,32,33}$ 


\section{CONCLUSIONS}

1. Excessive changes in the PBU pressure in lumbar movement control tests during lower limb exercise in young male reflect the inability to sustain isometric abdominal muscle contraction. These results can be classified as uncontrolled extension movement.

2. There is no unequivocal evidence confirming that asymptomatic individuals with incorrect movement patterns are bound to suffer from lumbar pain in the future. However, in order to limit the growing problem of LBP, prevention and therapy with the PBU in individuals with poor neuromuscular control of the lumbar spine should be helpful.

\section{Conflict of interest}

None declared.

\section{Ethical approval}

The research was approved by Bioethical Commision (KB31/2013).

\section{Funding}

This research did not receive any specific grant from funding agencies in the public, commercial, or not-for-profit sectors.

\section{References}

1 Zamani E, Kordi R, Nourian R, Noorian N, Memari $\mathrm{AH}$, Shariati $\mathrm{M}$. Low back pain functional disability in athletes; conceptualization and initial development of a questionnaire. Asian f Sports Med. 2014;5(4):e24281. https://doi.org/10.5812/asjsm.24281.

2 Middleton K, Fish DE. Lumbar spondylosis: clinical presentation and treatment approaches. Curr Rev Musculoskelet Med. 2009;2(2):94-104. https://doi.org/10.1007/ s12178-009-9051-x.

3 Schaller A, Froboese I. Movement coaching: study protocol of a randomized controlled trial evaluating effects on physical activity and participation in low back pain patients. BMC Muskulosketel Disord. 2014;15:391. https://doi.org/10.1186/1471-2474-15-391.

4 Helfenstein Junior $M$, Goldenfum MA, Siena C. Occupation low back pain. Rev Assoc Med Bras. 2010;56(5):583-589.

5 Freburger JK, Holmes GM, Agans RP, et al. The Rising Prevalence of Chronic Low Back Pain. Arch Intern Med. 2009;169(3):251-258. https://doi.org/10.1001/archinternmed.2008.543.

6 Tymecka-Woszczerowicz A, Wrona W, Kowalski PM, Hermanowski T. Indirect costs of back pain - Review. Pol Ann Med. 2015;22(2):143-148. https://doi.org/10.1016/j. poamed.2015.07.003.
7 Van Dillen L, Sahrmann S, Norton B, Caldwell CA, McDonnell MK, Bloom NJ. Movement system impairment-based categories for low back pain: stagelvalidation. F Orthop Sports Phys Ther. 2003;33(3):126-142. https://doi.org/10.2519/jospt.2003.33.3.126.

8 de Souza Petersen R, Marziale MHP. Low back pain characterized by muscle resistance and occupational factors associated with nursing. Rev Lat Am Enfermagem. 2014;22(3):386-393. https://doi.org/10.1590/01041169.3321.2428.

9 Chimenti RL, Scholtes SA, Van Dillen LR. Activity characteristics and movement patterns in people with and people without low back pain who participate in rotation-related sports. F Sport Rehabil. 2013;22(3):161-169. https://doi.org/10.1123/jsr.22.3.161.

10 Hadała M, Gryckiewicz S. The effectiveness of lumbar extensor training: local stabilization or dynamic strengthening exercises. A review of literature. Ortop Traumatol Rehabil. 2014;16(6):561-572. https://doi. org/10.5604/15093492.1135044.

11 Sahrmann S. Diagnosis and treatment of movement impairment syndromes. St Louis: Mosby; 2002.

12 Harris-Hayes M,VanDillen L,Sahrmann S.Classification, treatment and outcomes of a patient with lumbar extension syndrome. Physiother Theory Pract. 2005;21(3):181196. https://doi.org/10.1080/09593980500212987.

13 Comerford M, Mottram S. Kinetic Control: The Management of Uncontrolled Movement. Australia: Elsevier; 2012.

${ }_{14}$ Roussel N, Nijs J, Mottram S, Van Moorsel A, Truijen S, Stassijns G. Altered lumbopelvic movement control but not generalized joint hypermobility is associated with increased injury in dancers. A prospective study. Man Ther. 2009;14(6):630-635. https://doi.org/10.1016/j. math.2008.12.004.

15 Comerford M, Mottram S. Kinetic Control. The Management of Uncontrolled Movement. Book review. Physical Therapy in Sport. 2013;14(1):68. https://doi.org/10.1016/j.ptsp.2012.09.001.

16 Hadała M, Gryckiewicz S. Movement pattern and muscle balance as a source of lumbar spine health according to the concept of Kinetic Control. Pol Ann Med. 2014;21(2):152-157. https://doi.org/10.1016/j.poamed.2014.06.001.

17 Comerford MJ, Mottram SL. Movement and stability dysfunction - contemporary developments. Man Ther. 2001;6(1):15-26. https://doi.org/10.1054/math.2000.0388.

18 O'Sullivan P. Diagnosis and classification of chronic low back pain disorders: maladaptive movement and motor control impairments as underlying mechanism. Man Ther. 2005;10(4):242-255. https://doi.org/10.1016/j. math.2005.07.001.

19 Luomajoki H, Kool J, de Bruin E, Airaksinen O. Reliability of movement control tests in the lumbar spine. BMC Musculoskelet Disord. 2007;8:90. https://doi. org/10.1186/1471-2474-8-90.

20 Luomajoki H, Kool J, D de Bruin E, Airaksinen O. Movement control tests of the low back; evaluation of the 
difference between patients with low back pain and healthy controls. BMC Musculoskeletal Disord. 2008;9:170. https://doi.org/10.1186/1471-2474-9-170.

${ }_{21}$ Mok NW, Brauer SG, Hodges PW. Changes in lumbar movement in people with low back pain are related to compromised balance. Spine (Phila Pa 1976). 2011;36(1):E45-E52. https://doi.org/10.1097/ BRS.0b013e3181dfce83.

22 Hodges PW, Moseley GL. Pain and motor control of the lumbopelvic region: effect and possible mechanisms. $\mathcal{F}$ Electromyogr Kinesiol. 2003;13(4):361-370. https://doi. org/10.1016/S1050-6411(03)00042-7.

23 Monnier A, Heuer J, Norman K, Äng BO. Inter- and intra-observer reliability of clinical movement-control tests for marines. BMC Musculoskelet Disord. 2012;13:263. https://doi.org/10.1186/1471-2474-13-263.

24 Adams MA, Dolan P, Hutton WC. The lumbar spine in backward bendig. Spine (Phila Pa 1976). 1998; 13(9):10191026. https://doi.org/10.1097/00007632-198809000-00009.

25 Roussel NA, Daenen L, Vissers D, et al. Motor control and physical fitness training to prevent musculoskeletal injuries in professional dancers. 3rd International Conference on Movement Dysfunction, Edinburgh, UK. 30 October-1 November. Manual Therapy. 2009;14(1):22.

26 Azevedo DC, Lauria AC, Pereira AR, et al. Intraexaminer and interexaminer reliability of pressure biofeedback unit for assessing lumbopelvic stability during 6 lower limb movement tests. $\mathcal{F}$ Manipulative Physiol Ther. 2013;36(1):33-43. https://doi.org/10.1016/j. jmpt.2012.12.008.
27 Jull G, Richardson C, Toppenberg R, Comerford M, Bui B. Towards a measurement of active muscle control for lumbar stabilisation. Aust $\mathcal{F}$ Physiother. 1993;39(3):187-193. https://doi.org/10.1016/S0004-9514(14)60481-5.

28 Richardson C, Jull G, Toppenberg R, Comerford M. Techniques for active lumbar stabilisation for spinal protection: A pilot study. Aust $\mathcal{F}$ Physiother. 1992;38(2):105-112. https://doi.org/10.1016/S0004-9514(14)60555-9.

29 Panajbi MM. The stabilizing system of the spine. Part II. Neutral zone and instability hypothesis. J Spinal Disord. 1992;5(4):390-396. https://doi. org/10.1097/00002517-199212000-00002.

30 Panajbi MM. The stabilizing system of the spine. Part I. Function, dysfunction, adaptation, and enhancement. F Spinal Disord.1992;5(4):383-389. https://doi. org/10.1097/00002517-199212000-00001.

31 Panjabi MM. Clinical spinal instability and low back pain. F Electromyogr Kinesiol. 2003;13(4):371-379. https:// doi.org/10.1016/S1050-6411(03)00044-0.

32 Rajeswaran G, Turner M, Gissane C, Healy JC. MRI findings in the lumbar spines of asymptomatic elite junior tennis players. Skeletal Radiol. 2014;43(7):925-932. https://doi.org/10.1007/s00256-014-1862-1.

33 Alyas F, Turner M, Connell D. MRI findings in the lumbar spines of asymptomatic, adolescent, elite tennis players. Br $\mathcal{F}$ Sports Med. 2007;41(11):836-841. https:// doi.org/10.1136/bjsm.2007.037747. 